\title{
Optimization of China's Electricity Market Allocation Under the "Paris Agreement"
}

\author{
Kun Xiao \\ Research Center for Environment and Health \\ Zhongnan University of Economics and Law \\ Wuhan, China 430000 \\ School of Business Administration \\ Zhongnan University of Economics and Law \\ Wuhan, China 430000
}

\author{
Yi Wang \\ State Grid Xianning Electric Power Supply Corporation \\ Xianning, China, 437000
}

\author{
Jingdong Zhang* \\ Research Center for Environment and Health \\ Zhongnan University of Economics and Law \\ Wuhan, China 430000 \\ School of Business Administration \\ Zhongnan University of Economics and Law \\ Wuhan, China 430000 \\ *Corresponding Author
}

\begin{abstract}
China's carbon emission of coal-fired thermal power generation has accounted for nearly $40 \%$ of the country's carbon emissions. According to the "Paris Agreement", reducing carbon emissions from power generation has become a thorny issue in China. In addition to power generation technology transformation, the optimization of China's electricity market configuration is an important means to solve this problem. Aiming at carbon emission reduction and economic dispatching, this paper constructs a cross-regional power generation optimization configuration model in China to find the optimal compromise solution that meets the technical conditions. Studies have shown that within the feasible domain, stringent target setting can increase the benefits of carbon emission reduction and scheduling optimization. When the carbon emission reduction limit is close to 9\%, carbon emission reduction will reach 331 million tons, and the efficiency of dispatch optimization will reach 1.395 billion yuan. This paper has certain reference value for the scientific guidance and supervision of power generation by government officials, regulatory authorities and related enterprises.
\end{abstract}

Keywords-carbon emission reduction; configuration optimization; optimal compromise solution

\section{INTRODUCTION}

On September 3, 2016, President Xi Jinping signed the "Paris Agreement". In October 2017, the 19th National Congress of the Communist Party put forward the requirements of "promoting green development" and "building beautiful China." However, high carbon emissions have always been the thorny issue in Chinese economic construction. According to the "Global Carbon Budget 2017" issued by Global Carbon Project (GCP), China's carbon emissions ranked first in the world in 2016, reaching 10.136 billion tons, accounting for $28 \%$ of global emissions. According to the 2016 Statistics on National Economic and Social Development, China's coal-fired thermal power configuration and its electricity generation accounted for $64.04 \%$ and $72.23 \%$ respectively. In that year, thermal power generation was $4,437.07$ billion $\mathrm{kWh}$. According to the average coal consumption of electricity generation standard of $315 \mathrm{~g} / \mathrm{kWh}$, its carbon emissions were about 3.875 billion tons, accounting for $38.23 \%$ of national carbon emissions, which is close to $40 \%$. As one of the world's largest carbon emitters, China promises to reduce its carbon emission intensity per unit of GDP by $40 \%$ to $45 \%$ by 2020 compared to 2005 , while increasing the proportion of non-fossil energy in primary energy to $15 \%$ [1]. Therefore, reducing carbon emissions from power generation is an important part of fulfilling China's commitments in the Paris Agreement and an important issue that China must focus on in economic construction in the future.

The reason for China's large carbon emissions from power generation is that it is highly dependent on coal-fired thermal power [2]. According to studying the literature, it summarizes three ways to reduce carbon emissions from power generation. First, Hou Jianchao and Shi Dan (2014) believe that although some coal-fired power units in China have reached the world's advanced level, it is difficult to optimize the construction of transmission and distribution network and adjust the industrial structure of power consumption in the short term. China needs to coordinate regional differences and exert its strength in the power 
consumption intensity, transmission and distribution loss rate, power generation coal consumption rate and power generation structure of its industrial sector [2]. Second, Liu Zhenya (2017) believes that UHV grids across provinces, regions and even across countries and continents should be built to achieve the production and consumption allocation of clean energy in a larger geographical area, thereby increasing the proportion of clean energy generation [3]. Third, Li Canbing et al. (2011) believe that low-carbon should be used as a power dispatching target with the same weight as safety and economy to guide low carbon power generation in the dispatching command [4]. In short, on the basis of coordinating multiple approaches, implementing carbon emission reduction policies is the key to achieving China's carbon emission reduction targets.

At present, China has implemented carbon emission reduction policies in many aspects. In terms of technology, China will make bold efforts to transform and shut down backward coal-fired power plants and reduce coal consumption of coal-fired power generation. In terms of planning, large-scale investment will be made in the construction of wind power generation, photovoltaic power and other clean energy generation, and the improvement of ultra-high voltage power grids, so as to improve the power transmission capacity across regions. In terms of industry management, power generation planning is inclined to renewable energy and renewable energy subsidies are provided. In terms of market guidance, power generation rights trading, carbon emission rights trading, "green card" trading, etc. should be established to guide the improvement of power generation efficiency and optimization of power generation structure. The above measures have achieved remarkable results [5], [6]. From a national perspective, there are still three imbalances in the production and operation of coal-fired thermal power in China, which restricts further carbon reduction in power generation. First, compared with other types of power generation, the coal-fired thermal power generation plans too high, and it has occupied the clean energy consumption space such as hydropower, wind power and photovoltaic in the corresponding areas. Second is the horizontal comparison between regions, and the allocation of coal-fired thermal power generation plans is uneven. Third, different regions and different types of power generation is not balanced in the grid purchase price. The scheduling method of economic dispatching does not necessarily meet the requirements of carbon emission reduction. Among the above three aspects, the imbalance of power generation plan distribution is the main contradiction, which is caused by both technical conditions and industrial management.

From the perspective of technical conditions, China's primary energy structure is characterized by "multiple coal, less oil, and lack of gas". In addition, coal-fired thermal power has been relatively economical and mature in terms of investment, regulatory performance, safety control and other aspects. It is not realistic to change China's power generation structure and replace coal-fired thermal power in a large scale in a short time. At the same time, as Liu Zhenya (2013) explained, the regional allocation of electricity production and consumption in China has caused the pattern of "Westto-East Power Transmission". The large-scale "West-to-East Power Transmission" needs the support of coal-fired thermal power in key nodes of the power grid [7]. However, due to technical factors such as transmission channels and unit adjustment capabilities, some problems of "abandoning wind", "abandoning light" and "abandoning water" have emerged.

From the perspective of industrial management, it can be divided into two aspects. On the one hand, as Zhang Xian et al. (2014) mentioned, in the early years, China faced the power shortage. At that time, it was urgent to encourage the investment and construction of coal-fired thermal power generation. The government authorities have made commitments to ensure the power generation plan for some coal-fired thermal power generators [5]. The power generation plan is issued by the provincial government departments, and there is "local protection" of industrial management. As a result, thermal power units in areas with high coal consumption have more power generation plans than thermal power units in areas with low coal consumption. On the other hand, it is one of the goals of power dispatching department to make economic dispatch and optimize the power purchase cost of power grid companies. In practice, the dispatching departments of the provincial power grids always prioritize the lowest purchase cost under the limitation of their power generation plans. The coal-fired power generation in some provinces has high coal consumption, but the on-grid electricity price is low. As a result, the optimization direction of electricity purchase expense in some provinces is inconsistent with the direction of power generation carbon emission reduction, which objectively forms an obstacle to the carbon emission reduction of power generation. Therefore, in order to ensure the initiative of the power grid dispatching department, the optimization of power generation configuration with the goal of carbon emission reduction needs to be compromised with economic dispatching targets.

In addition, the implementation of carbon emission reduction targets for power generation, whether it should be assigned to the industry or allocated to the provinces is still controversial [8], [9], [10]. From the perspective of implementation, the provinces are the implementers of carbon emission reduction for power generation. From the perspective of industry, the differences in power generation technology conditions and on-grid tariffs in various provinces make the superposition of the optimal compromise solutions for the carbon emission reduction of power generation and economic dispatch in each province not necessarily. Therefore, it is necessary to break the interprovincial barriers, and seek a compromise solution for carbon emission reduction and economic dispatching targets across the region and the whole industry. Since China's provincial power grid companies belong to the State Grid Corporation and China Southern Power Grid Corporation respectively, if the total power purchase cost of the grid company can be reduced under the compromise, even if the electricity purchase costs of some provinces may increase, the State Grid Corporation or China Southern Power Grid 
Corporation will have subjective initiative to implement the optimal compromise solution, so as to implement optimal power generation configuration.

Based on this, this paper believes that to control the carbon emission of power generation, it is necessary to coordinate the differences of power production technologies in different regions, take into account the carbon emission reduction of power generation and economic dispatching objectives, and find the optimal compromise solution that meets the technical constraints, namely, the optimal power generation dispatching scheme, on the premise of satisfying the safety and stability of power grid. The power generation plans and the implementation of dispatching plans should break the geographical barriers and be jointly promoted by the whole region and the whole industry. Based on the current research status, this paper will construct a configuration optimization model, conduct empirical analysis, and then give conclusions and recommendations.

\section{MODEL CONSTRUCTION}

This paper will apply the theory and method of operations research to build a multi-objective optimization model to discuss the optimization of power generation configuration in China.

\section{A. Objective Function}

- The objective function of carbon emission reduction of Power generation

Taking the province as the unit and the time as the time span, the objective function of the minimum carbon generation of total power generation is formula (1):

$$
\min \sum_{i=1}^{n} C_{i t}
$$

In formula (1), $C_{i t}$ is the carbon emission reduction of power generation in $i$ Province in $t$. Carbon emission of power generation is directly related to local thermal power generation and coal consumption per unit of power generation (or power supply). Formula (1) can be further changed to formula (2):

$$
\min \sum_{i=1}^{n} C_{i t}=\min \sum_{i=1}^{n}\left(v \cdot \omega_{i t} \cdot F_{i t}\right)
$$

In formula (2), ${ }^{v}$ is carbon emission coefficient of standard coal. $\omega_{i t}$ is the standard coal consumption of power generation side in $i$ Province in $t$. According to different demands, the standard coal consumption of generating units can be used, or the standard coal consumption of generating units can be used, but the statistical caliber of selected coal consumption and electricity should be consistent. According to the industry standard, the calorific value of standard coal is converted, namely, $v=2.7725$.
- Economic dispatch objective function

Since the nation faces the priority acquisition of renewable energy power generation, the grid target should set the economic target to the lowest total cost of thermal power purchase, as shown in formula (3):

$$
\min \sum_{i=1}^{n}\left(p_{f i t} \cdot F_{i t}\right)
$$

In formula (3), $p_{\text {fit }}$ is the sightcing price of coal-fired thermal power in $i$ Province in $t$.

\section{B. Constraints}

In order to achieve the minimum goal of total carbon emission of power generation, the constraints of research are given: the constraints of power generation capacity; grid balance restrictions; cross-provincial and trans-regional power transmission restrictions.

- The constraints of power generation capacity

$$
H_{i t \max } \text { and } H_{i t \min }, F_{i t \max } \text { and } F_{i t \min }, L_{i t \max } \text { and } L_{i t \min } \text {, }
$$
$W_{i t \max }$ and $W_{i t \min }$ are the maximum and minimum power generation capacity of hydropower, thermal power, nuclear power, wind power and photovoltaic in $i$ Province in $t$. As can be seen from the generation arrangement, the generation capacity limit should not be broken, as expressed in formula (4):

$$
\left\{\begin{array}{l}
H_{i t \min } \leq H_{i t} \leq H_{i t \max } \\
F_{i t \text { min }} \leq F_{i t} \leq F_{i t \max } \\
W_{i t \text { min }} \leq W_{i t} \leq W_{i t \max } \\
L_{i t \min } \leq L_{i t} \leq L_{i t \max }
\end{array}\right.
$$

- Grid balance restrictions

Grid dispatching requires the system to have sufficient static and transient stability, and has the ability to adjust. Therefore, different types of power generation must maintain a certain proportion of the total power in a province, that is, the adjustment coefficient of power generation structure. The relationship between the adjustment coefficient and the corresponding power generation scale is expressed as the formula (5):

$$
\left\{\begin{array}{c}
\alpha_{1 i t} \leq \frac{H_{i t}}{H_{i t}+F_{i t}+W_{i t}+L_{i t}+X_{i t}} \leq \beta_{1 i t} \\
\alpha_{2 i t} \leq \frac{F_{i t}}{H_{i t}+F_{i t}+W_{i t}+L_{i t}+X_{i t}} \leq \beta_{2 i t} \\
\alpha_{3 i t} \leq \frac{W_{i t}}{H_{i t}+F_{i t}+W_{i t}+L_{i t}+X_{i t}} \leq \beta_{3 i t}
\end{array}\right.
$$


In formula (5), $X_{i t}$ is the amount of electricity purchased (positive at buy, negative at sell) through inter-provincial tie lines of $i$ Province in $t, \beta_{1 i t}, \beta_{2 i t}, \beta_{3 i t}$ are the maximum proportion limit of hydropower, thermal power, wind power and photovoltaic in the total on-grid power generation in $i$ Province in $t$. $\alpha_{1 i t}, \alpha_{2 i t}, \alpha_{3 i t}$ are the maximum proportion limit of hydropower, thermal power, wind power and photovoltaic in the total on-grid power generation in $i$ Province in $t$.

The thermal and electric correlation formula in formula (5) can be equivalent rewritten to formula (6):

$$
\frac{F_{i t}}{\beta_{i t}} \leq\left(G_{i t}+K_{i t}\right) \leq \frac{F_{i t}}{\alpha_{i t}}
$$

In formula (6), $G_{i t}$ is on-grid energy of power generation of $i$ Province in $t$. $K_{i t}$ is the electric quantity of $i$ output to the other provinces in $t$ (Taking the output as a positive value, and the receiving quantity as a negative value).

The author test formula (6) in all provinces of China (except Taiwan), and there is formula (7):

$$
\sum_{i=1}^{n} \frac{F_{i t}}{\beta_{i t}} \leq\left(\sum_{i=1}^{n} G_{i t}+\sum_{i=1}^{n} K_{i t}\right) \leq \sum_{i=1}^{n} \frac{F_{i t}}{\alpha_{i t}}
$$

Across the country, the amount of electricity sent and received between provinces cancels out. That is, $\sum_{i=1}^{n} K_{i t}=0$

. Formula (7) is equivalent to formula (8).

$$
\sum_{i=1}^{n} \frac{F_{i t}}{\beta_{i t}} \leq \sum_{i=1}^{n} G_{i t} \leq \sum_{i=1}^{n} \frac{F_{i t}}{\alpha_{i t}}
$$

- Cross-provincial transmission restrictions

There is more than one tie line in a province, and the voltage level may be different. The cross-province transmission line may have multiple changes in direction and traversal in the monthly time. This model can simulate the trans-provincial transmission factors according to the "black box", and the trans-provincial transmission restriction problem is simplified as follows: the net purchase of electricity in a single province for a specified length of time does not exceed a certain limit, ie, formula (9).

$$
X_{i t} \leq X_{i t \max }
$$

In formula (9), $X_{i t \max }$ is the maximum limit of net power purchased under the condition that the inter-provincial tie line does not exceed the limit in $i$ Province in $t$.

\section{Model Solution}

Based on the above objective function and constraints, the optimal power generation configuration model targeting low carbon and economy is expressed as formula (10).

$$
\begin{aligned}
& \min \left[\begin{array}{l}
\sum_{i=1}^{n}\left(v \cdot \omega_{i t} \cdot F_{i t}\right) \\
\sum_{i=1}^{n}\left(p_{f i t} \cdot F_{i t}\right)
\end{array}\right] \\
& \text { s.t. }\left\{\begin{array}{l}
\sum_{i=1}^{n} \frac{F_{i t}}{\beta_{i t}} \leq \sum_{i=1}^{n} G_{i t} \\
-\sum_{i=1}^{n} \frac{F_{i t}}{\alpha_{i t}} \leq-\sum_{i=1}^{n} G_{i t} \\
\sum_{i=1}^{n}\left(v \cdot \omega_{i t} \cdot F_{i t}\right) \leq C_{t} \\
F_{i t \min } \leq F_{i t} \leq F_{i t \max }
\end{array}\right.
\end{aligned}
$$

In formula (10), ${ }^{C_{t}}$ in the restriction condition is China's power generation carbon emission target value in $t . F_{i t \min }$, $F_{i t \max }$ are the minimum and maximum thermal power generation of $i$ Province in $t$.

The multi-objective optimization model has many methods to solve, such as using the least squares method or the weighted value method to convert multi-objective optimization into single-objective optimization, or comparing multiple solution sets to find the Pareto solution [11]. This paper believes that low carbon and economy are a set of contradictory but mutually compromised goals in the optimal allocation of power generation. It is based on industrial goals and seeks compromises in the differences in production technology capabilities and technical and economic indicators in different provinces. Therefore, the optimal compromise solution is adopted to solve the model.

$J$ is the mathematical formula of the standard expression for multi-objective linear programming problem, as shown in formula (11).

$$
\begin{aligned}
& J=\max C \cdot x \\
& \text { s.t. }\left\{\begin{array}{l}
A \cdot x \leq B \\
A_{e q} \cdot x=B_{e q} \\
x_{\text {min }} \leq x \leq x_{\text {max }}
\end{array}\right.
\end{aligned}
$$

In formula (11), the objective function and the constraint conditions are matrix expressions. $C \cdot x$ can be regarded as a set of objective functions $f_{i}(x)=c_{i} \cdot x$ ( $i$ is the natural number, $\quad i=1,2,3 \ldots, n \quad$ ). $A \cdot x \leq B \quad$ is inequality 
constraint, $A_{e q} \cdot x=B_{e q}$ is equality constraint, and $x_{\min } \leq x \leq x_{\max }$ is assignment constraint.

The optimal compromise solution understands the $f_{i}(x)=c_{i} \cdot x$ of each objective function ( $i$ is natural number, $i=1,2,3 \ldots, n)$ as the profit distribution of the $i$, and the optimization problem can be considered as the maximum distribution of the interests of all parties. Under the constraints, it is impossible to maximize the interests of each party, and the parties need to make appropriate compromises to arrive at the only optimal compromise solution. The optimal compromise solution is solved by:

In the first step, the $f_{k}$ of the optimal solution can be obtained by solving each objective function separately $(k$ is natural number, $k=1,2,3 \ldots, n$ ).

In the second step, separate objective function is constructed by normalization, as shown in formula (12):

$$
f(x)=-\sum_{k=1}^{n}\left(\frac{1}{f_{k}} \cdot c_{k} \cdot x\right)
$$

Third, the optimal compromise solution of $J$ can be directly solved by solving the single-objective linear programming problem as shown in formula (13):

$$
\begin{aligned}
& J=\max f(x) \\
& \text { s.t. }\left\{\begin{array}{l}
A \cdot x \leq B \\
A_{e q} \cdot x=B_{e q} \\
x_{\text {min }} \leq x \leq x_{\text {max }}
\end{array}\right.
\end{aligned}
$$

According to the above solution method, Matlab software is used to programmatically solve the optimal configuration of power generation. Since the grid communication in each province is not omnidirectional, and the trans-provincial transmission trend varies according to the operation mode (ie, the province is used as the transmission end grid or the end grid under the optimal solution), the transmission restriction condition has no fixed expression and is solved. After the optimal compromise solution of the optimal configuration model for power generation, it is also necessary to check whether the operation mode corresponding to the optimal solution can meet the transmission limit.

\section{EMPIRICAL ANALYSIS}

\section{A. Basic Data}

Due to the lag of China's statistics on the power industry (The current statistics are China's power industry data in 2015. Data for 2016 are yet to be released by the end of 2018). Therefore, this paper uses the 2016 China Power Yearbook published in the second half of 2017. Therefore, the empirical analysis uses the power industry data in 2015.
There are many administrative provinces in China. In order to simplify the analysis and integrate the actual distribution of power grids, regional power, electricity balance and energy transmission channels in China's power grids, this paper assigns the provinces with similar scheduling, transmission capacity, power generation technology and on-grid tariffs as regions. The implementation of power generation resource optimization tasks is carried out on a regional basis. China (excepting Taiwan) is divided into the following eight regions: Xinjiang, Northwest (including Gansu, Ningxia, Shaanxi, Qinghai), Inner Mongolia, North China (including Shanxi, Hebei, Beijing, Tianjin, Shandong), Northeast (including Heilongjiang, Jilin, Liaoning), South (including Guangdong, Guangxi, Yunnan, Guizhou, Hainan), Central China (including Sichuan, Chongqing, Henan, Hubei, Hunan, Jiangxi), East China (including Anhui, Shanghai, Jiangsu, Fujian, Zhejiang). The installed capacity in Tibet is small and the ability to interact with other regions is weak. As an isolated network, it is not included in the solution.

According to the parameters of the set model, the data to be counted includes: the total social power consumption of each region, the coal-fired thermal power generation capacity, and the on-grid price of coal-fired thermal power. All data should be unified to the on-grid statistics.

The "combustion capacity of coal-fired thermal power generation" can't be directly obtained, but the technical and economic indicators of power generation available in the yearbook statistics are: "the installed capacity of coal-fired thermal power". In order to unify the statistical caliber of the on-grid side, this paper defines a new indicator for the "using the on-grid power generation equipment" (hereinafter referred to as "the number of hours of power generation"), which is used to convey the expression "with the installed capacity of coal-fired thermal power". "Coal-fired thermal power generation capacity" is as shown in formula (14):

$$
S=\frac{W}{R}
$$

In formula (14), $S$ refers to "hours of power generation on the grid". $W$ refers to the on-grid capability of the unit under investigation, and $R$ indicates the capacity of the unit under investigation. In this way, the "combustion capacity of coal-fired thermal power generation" is expressed, and the optimal compromise solution is transformed into an optimized solution for the number of hours of power generation in each region. The installed capacity of each region in 2015 is shown in "Table I".

It is known from "Table I" that the average coal consumption of power supply in Xinjiang, Northwest China, Inner Mongolia and other regions is high, but the on-grid electricity price of thermal power is low. The average coal supply consumption in the regions of the Southern, Central China, and East China is low, but the on-grid price of thermal power is high. The goal of simply pursuing carbon emission reduction for power generation will certainly 
contradict the economic dispatch targets of some of the

above regions.

TABLE I. Distribution OF INSTALLED CAPACITY IN VARIOUS REgIONS OF CHINA IN 2015 (UNIT: BILLION KiLOWATTS)

\begin{tabular}{|c|c|l|l|l|}
\hline Region & $\begin{array}{c}|c| \\
\text { Electricity } \\
\text { consumption in the } \\
\text { whole society (trillion } \\
\text { kwh) }\end{array}$ & $\begin{array}{c}\text { Coal-fired thermal power } \\
\text { installed capacity } \\
\text { (100 million kw) }\end{array}$ & $\begin{array}{c}\text { Average power supply } \\
\text { standard coal } \\
\text { consumption } \mathbf{( g / k w h )}\end{array}$ & $\begin{array}{c}\text { Average on-grid price of } \\
\text { coal-fired thermal power } \\
\text { (yuan/mwh) }\end{array}$ \\
\hline 1-Xinjiang Province & 0.2160 & 0.4199 & 325.0000 & 262.000 \\
\hline 2-Northwest China & 0.3857 & 0.7168 & 323.4708 & 337.190 \\
\hline 3-Inner Mongolia & 0.2543 & 0.7263 & 337.0000 & 307.000 \\
\hline 4-Northern China & 1.1784 & 2.1292 & 318.0210 & 414.466 \\
\hline 5-Northeast China & 0.3087 & 0.6898 & 315.7741 & 404.341 \\
\hline 6-Southern China & 0.9530 & 1.3522 & 316.1639 & 462.854 \\
\hline 7-Central China & 0.9947 & 1.5798 & 317.0940 & 444.330 \\
\hline 8-Eastern China & 1.3567 & 2.4375 & 301.5396 & 439.306 \\
\hline
\end{tabular}

${ }^{\text {a. }}$ Source: The author calculated and compiled according to the "2016 China Power Yearbook" and the "Notice of the National Development and Reform Commission on Reducing the On-grid Electricity Price of Coal-

The transmission capacity of each region in 2015 is shown in "Table II", which is used to check whether the optimal solution meets the transmission restriction conditions.

TABLE II. LIST OF ChINA'S CROSS-REGIONAL TRANSMISSION CHANNELS AND TRANSMISSION CAPACITY IN 2015

\begin{tabular}{|c|l|l|}
\hline & Receiving power grid* $\mathbf{1 0 0}$ million kwh) & Sending power grid* (100 million kwh) \\
\hline 1-Xinjiang Province & -823.44 & 823.44 \\
\hline 2-Northwest China & -1383.38 & 1679.82 \\
\hline 3-Inner Mongolia & -370.55 & 617.58 \\
\hline 4-Northern China & -1819.80 & 1358.68 \\
\hline 5-Northeast China & -555.822 & 720.51 \\
\hline 6-Southern China & -247.032 & 247.03 \\
\hline 7-Central China & -1860.97 & 4476.22 \\
\hline 8-Eastern China & -2862.28 & 0 \\
\hline
\end{tabular}

Source: The authors collated according to the UHV AC-DC Grid (Liu Zhenya, 2013). After checking with the actual situation, the special and ultra-high voltage transmission capacity between China's regions in 2015 is consistent with this data.

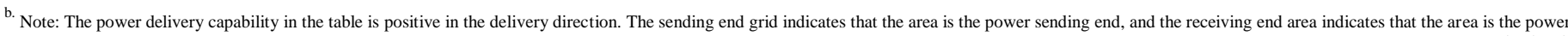

Finally, it is also necessary to ask the relevant dispatching agencies to obtain the value of the adjustment

$$
\left\{\begin{array}{l}
\alpha_{i t}=[0.748,0.673,0.786,0.865,0.757,0.484,0.467,0.805,0.01]^{T} \\
\beta_{i t}=[0.872,0.778,0.893,0.962,0.861,0.546,0.603,0.9,0.1]^{T}
\end{array}\right.
$$

\section{B. The Evaluation and Effect Evaluation of the Optimal \\ Compromise Solution}

Based on the above model setting, model solving method and basic data, Matlab software was used to carry out empirical simulation. Before solving the model, it is necessary to make assumptions about the upper and lower limits of the "power generation hours" of thermal power in each region.

Hypothesis 1: assuming that there are no restrictions on carbon emission targets; assuming that the "power generation hours" in all regions are uniformly set to: the lower limit is 0 hours and the upper limit is 5000 hours. The optimal compromise solution obtained at this time is compared with "Table II" to obtain the power transmission capability check result, as shown in "Table III". 
TABLE III. OPTIMAL COMPROMISE SOLUTION OF HyPOTHESIS 1

\begin{tabular}{|c|l|l|l|l|}
\hline Region & $\begin{array}{c}\text { Optimal compromise solution } \\
\text { (the number of hours of coal-fired } \\
\text { thermal power generation on-grid) }\end{array}$ & $\begin{array}{c}\text { Minimum delivery capacity } \\
\text { sending out (100 million kwh) }\end{array}$ & $\begin{array}{c}\text { Maximum delivery capacity } \\
\text { sending out } \mathbf{( 1 0 0} \text { million } \\
\text { kwh) }\end{array}$ & $\begin{array}{c}\text { Transmission } \\
\text { capacity check }\end{array}$ \\
\hline 1-Xinjiang Province & 4,998 & 246.79 & 645.78 & Pass \\
\hline 2-Northwest China & 4,329 & 131.44 & 753.71 & Pass \\
\hline 3-Inner Mongolia & 4,719 & 1026.91 & 1636.41 & Restricted \\
\hline 4-Northern China & 4,264 & -2345.40 & -1286.96 & Pass \\
\hline 5-Northeast China & 3,781 & -57.35 & 358.81 & Pass \\
\hline 6-Southern China & 4,026 & -13.12 & 1717.23 & Pass \\
\hline 7-Central China & 3,578 & -574.13 & 2155.45 & Pass \\
\hline 8-Eastern China & 4,177 & -2428.18 & -919.94 & Pass \\
\hline
\end{tabular}

It can be seen from "Table III" that under this assumption, although the optimal compromise solution exists, the transmission capability check of some regions cannot be passed. The optimal solution does not have practical feasibility and needs to be changed in a targeted manner.

Hypothesis 2: Assuming that there are no restrictions on carbon emission targets; assuming that the minimum number of "hours to generate electricity on-grid" in all regions is
3800 hours; for the transmission bayonet in some regions, it is assumed that except for Inner Mongolia, the upper limit of "number of hours spent on electricity generation" in all regions is 4500 hours, the "number of hours of electricity generation" in Inner Mongolia is 4,200 hours. The optimal compromise solution obtained at this time, and the transmission capacity check result is obtained by comparing "Table II", as shown in "Table IV".

TABLE IV. OPTIMAL COMPROMISE SOLUTION OF HYPOTHESIS 2

\begin{tabular}{|c|l|l|l|l|}
\hline \multicolumn{1}{|c|}{ Region } & $\begin{array}{c}\text { Optimal compromise solution } \\
\text { (The number of hours of coal-fired } \\
\text { thermal power generation on-grid) }\end{array}$ & $\begin{array}{c}\text { Minimum delivery capacity } \\
\text { sending out (100 million } \\
\mathbf{k W h})\end{array}$ & $\begin{array}{c}\text { Maximum delivery capacity } \\
\text { sending out (100 million kWh) }\end{array}$ & $\begin{array}{c}\text { Transmission } \\
\text { capacity check }\end{array}$ \\
\hline 1-Xinjiang Province & 4,436 & -23.78 & 330.35 & \\
\hline 2-Northwest China & 4,415 & 210.93 & 845.60 & 1149.11 \\
\hline 3-Inner Mongolia & 4,168 & 610.68 & -784.96 & Pass \\
\hline 4-Northern China & 4,468 & -1894.01 & 958.79 & Pass \\
\hline 5-Northeast China & 4,439 & 470.16 & 1254.00 \\
\hline 6-Southern China & 3,860 & -405.08 & 3505.13 \\
\hline 7-Central China & 3,977 & 471.15 & -1983.94 \\
\hline 8-Eastern China & 3,825 & -3365.29 & Pass \\
\hline
\end{tabular}

From "Table IV", it is assumed that the optimal compromise solution of Hypothesis 2 can meet the transmission capacity limitation and has practical feasibility. At the same time, it can be seen that among the eight regions examined, the optimal compromise solution of five regions, such as Xinjiang, is closer to the upper limit of the assignment interval. The optimal compromise solution for the three regions in the south is closer to the lower limit of the assignment interval, which is the installed capacity and coal consumption of each region. The result of the compromise with the on-grid tariff level is consistent with the theoretical analysis. The carbon emission reduction and grid-connected costs for further evaluation of this optimal compromise are shown in "Table V".

TABLE V. Evaluation of the Optimal EFFect of the Optimal Compromise SOlution

\begin{tabular}{|c|l|l|l|l|l|l|}
\hline \multicolumn{1}{|c|}{ Region } & $\begin{array}{c}\text { Actual carbon } \\
\text { emissions } \mathbf{( 1 0 0} \\
\text { million tons) }\end{array}$ & $\begin{array}{c}\text { Optimal compromise } \\
\text { solution carbon emissions } \\
\mathbf{( 1 0 0} \text { million tons) }\end{array}$ & $\begin{array}{c}\text { Carbon emission } \\
\text { reduction* } \mathbf{1 0 0} \\
\text { million tons) }\end{array}$ & $\begin{array}{c}\text { Actual fees } \\
\mathbf{1 0 0} \text { million } \\
\text { yuan) }\end{array}$ & $\begin{array}{c}\text { Optimal compromise } \\
\text { solution on-grid fees } \\
\mathbf{( 1 0 0} \text { million yuan) }\end{array}$ & $\begin{array}{c}\text { Cost reduced } \\
\text { ** } \mathbf{( 1 0 0} \\
\text { million yuan) }\end{array}$ \\
\hline 1-Xinjiang Province & 1.8625 & 1.6785 & 0.1840 & 5.4155 & 4.8805 \\
\hline 2-Northwest China & 2.7506 & 2.8383 & -0.0878 & 10.3416 & 10.6716 \\
\hline 3-Inner Mongolia & 3.1973 & 2.8287 & 0.3686 & 10.5055 & 9.2945 \\
\hline 4-Northern China & 8.7422 & 8.3888 & 0.3534 & 41.0943 & 39.4330 \\
\hline 5-Northeast China & 2.1631 & 2.6810 & -0.5179 & 9.9901 & 12.3822 \\
\hline 6-Southern China & 4.3644 & 4.5752 & -0.2108 & 23.0455 & 24.1584 \\
\hline 7-Central China & 5.1439 & 5.5229 & -0.3790 & 25.9977 & 27.9134 \\
\hline
\end{tabular}




\begin{tabular}{|c|l|l|l|l|l|l|}
\hline Region & $\begin{array}{c}\text { Actual carbon } \\
\text { emissions (100 } \\
\text { million tons) }\end{array}$ & $\begin{array}{c}\text { Optimal compromise } \\
\text { solution carbon emissions } \\
\text { (100 million tons) }\end{array}$ & $\begin{array}{c}\text { Carbon emission } \\
\text { reduction* } \mathbf{1 0 0} \\
\text { million tons) }\end{array}$ & $\begin{array}{c}\text { Actual fees } \\
(\mathbf{1 0 0} \text { million } \\
\text { yuan) }\end{array}$ & $\begin{array}{c}\text { Optimal compromise } \\
\text { solution on-grid fees } \\
\text { (100 million yuan) }\end{array}$ & $\begin{array}{c}\text { Cost reduced } \\
* * \text { (100 } \\
\text { million yuan) }\end{array}$ \\
\hline 8-Eastern China & 8.5959 & 7.7953 & 0.8006 & 45.1694 & 40.9624 & \\
\hline Total & 36.8198 & 36.3087 & 0.5111 & 171.5597 & 169.6960 & 1.2070 \\
\hline
\end{tabular}

*Note: In the column "Carbon emission reduction", positive numbers indicate emission reductions, and negative numbers indicate increased emissions.

b. **Note: In the column "Reduction Costs", a positive number indicates a decrease in cost and a negative number indicates an increase in cost.

It can be seen from "Table $\mathrm{V}$ " that if the dispatching department strictly arranges the coal-fired thermal power production according to the optimal compromise solution under the assumption conditions, it can reduce the carbon emissions by about 50 million tons compared with the year (2015). The row is about $1.39 \%$. At the same time, under the optimal compromise solution, the cost of coal-fired thermal power grid connection will be reduced by about 186 million yuan, a decrease of about $1.09 \%$.

Compared with the original scheduling method, the optimal compromise solution can make the grid gain more revenue. In theory, it can encourage the grid dispatching department to schedule production according to the optimal compromise solution for economic purposes. It should be noted that, assuming that hypothesis 2 does not set a goal to reduce carbon emissions. As shown in "Table IV", the optimal compromise solution of some regions is close to the lower limit of its assignment limit, and the optimal compromise solution of some regions is closer to the upper limit of its assignment limit. Therefore, the optimal compromise solution does not mean that the carbon emission reduction potential is fully released, and the limit target can be introduced. Namely, the assignment of $C_{t}$ in (10) is adjusted to obtain a new optimal compromise solution.

Hypothesis 3: Based on the condition setting of Hypothesis 2, the target of increasing carbon emissions is set to: $9 \%$ carbon reduction of power generation. The optimal compromise solution obtained at this time, and the transmission capacity check result is obtained by comparing "Table II", as shown in "Table VI".

TABLE VI. OPTIMAL COMPROMISE SOLUTION OF HYPOTHESIS 3

\begin{tabular}{|c|c|c|c|c|}
\hline Region & $\begin{array}{c}\text { Optimal compromise solution } \\
\text { (the number of hours of coal-fired thermal } \\
\text { power generation on-grid) }\end{array}$ & \begin{tabular}{|c|} 
Minimum delivery capacity \\
sending out (100 million \\
kwh)
\end{tabular} & \begin{tabular}{|c|} 
Maximum delivery \\
capacity sending out $(100$ \\
million kwh)
\end{tabular} & $\begin{array}{c}\text { Transmission } \\
\text { capacity check }\end{array}$ \\
\hline 1-Xinjiang Province & 3,800 & -330.16 & -26.82 & Pass \\
\hline 2-Northwest China & 3,800 & -355.92 & 190.31 & Pass \\
\hline 3-Inner Mongolia & 3,800 & 331.94 & 822.78 & Pass \\
\hline 4-Northern China & 3,800 & -3373.44 & -2430.29 & Pass \\
\hline 5-Northeast China & 3,800 & -42.13 & 376.13 & Pass \\
\hline 6-Southern China & 3,878 & -361.75 & 1305.21 & Pass \\
\hline 7-Central China & 3,800 & 8.62 & 2907.90 & Pass \\
\hline 8-Eastern China & 3,800 & -3432.97 & -2060.79 & Pass \\
\hline
\end{tabular}

It is known from "Table VI" that it is assumed that the optimal compromise solution of hypothesis 3 can meet the transmission capacity limitation and has practical feasibility.
The carbon emission reduction and grid-connected costs for further evaluation of this optimal compromise are shown in "Table VII":

TABLE VII. EVALUATION OF THE OPTIMAL EFFECT OF THE OPTIMAL COMPROMISE SOLUTION

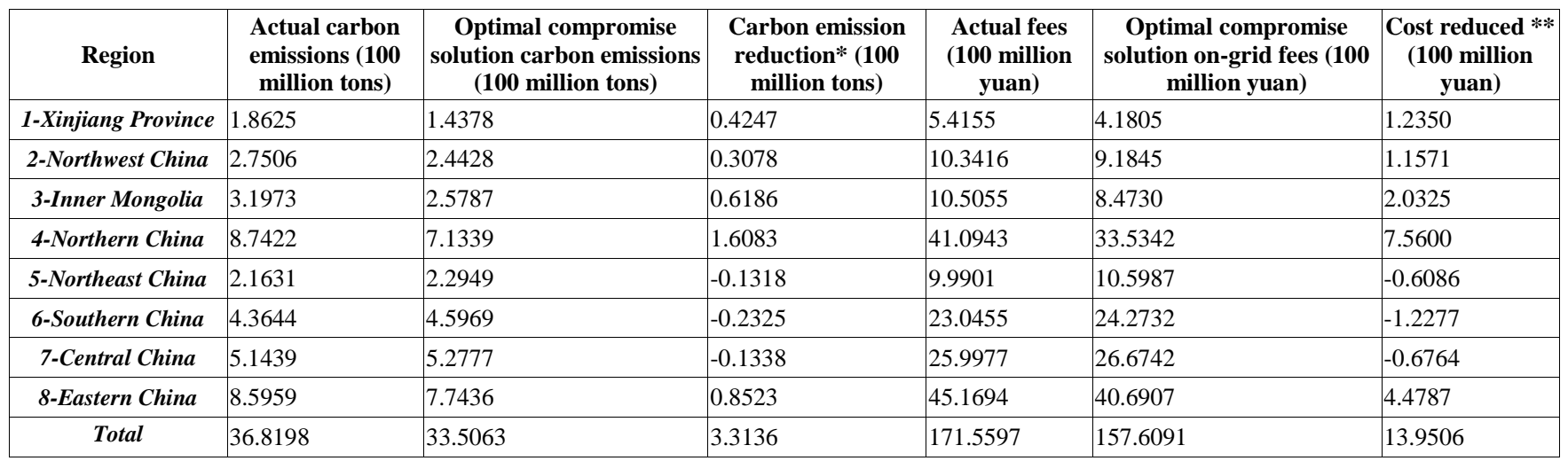

*Note: In the column "Carbon emission reduction", positive numbers indicate emission reductions, and negative numbers indicate increased emissions. 
It can be seen from "Table VII" that if the dispatching department strictly arranges coal-fired thermal power generation according to the optimal compromise solution under the assumption conditions, it can achieve the current hypothetical carbon emission reduction target: the actual carbon emission reduction is about 331 million tons compared with the observed year (2015), with a reduction rate of $9 \%$. Under the scheduling method of the optimal compromise solution, the cost of coal-fired thermal power grid connection will be reduced by about 1.395 billion yuan, a decrease of about $8.13 \%$.

Compared with the original actual scheduling method, the optimal compromise solution can make the grid gain more revenue. In theory, it can stimulate the grid dispatching department to schedule production according to the optimal compromise solution for economic purposes. As the carbon emission reduction target is more stringent, the optimal compromise solution of almost all regions is the lower limit of parameters, which indicates the limit of the carbon emission reduction target under the technical conditions of the year studied (2015).

In terms of carbon emission reduction effect and scheduling economic indicators, it is assumed that the optimal compromise solution of hypothesis 3 has obvious superiority compared with the optimal compromise solution of hypothetical hypothesis 2 , which is derived from the assumption of conditional change of hypothesis 3, that is, under the goal, the optimal solution first needs to meet the carbon emission reduction targets and then compromise with the economic goals. The reason why the grid-connection cost of coal-fired power in hypothesis 3 is lower than that in hypothesis 2 is that the more stringent carbon emission reduction target makes the optimal compromise solution value of almost all regions decrease as a whole.

\section{CONCLUSION}

In this paper, the power generation allocation optimization model is constructed with the minimum carbon emission target of power generation. Through finding the optimal compromise solution, the optimal allocation of power generation in China is studied. The main conclusions are as follows:

The carbon emission reduction target of power generation needs to be compromised with the economic dispatch target. It should also break down the geographical barriers and seek the best compromise solution of the power generation industry.

In the south, Inner Mongolia and other regions, there is a bayonet for the delivery or input of electric energy. It is necessary to adjust the value of the power generation plan limit. The allocation range of other provinces and regions should be adapted to the transmission capacity.

The effect of optimizing a compromise solution is related to the severity of the target setting. Under the constraints of the power generation plan assumed in this paper (hypothesis 2 and hypothesis 3), when the carbon-free emission reduction target is set (hypothesis 2), the optimized scale of carbon emission reduction and economic dispatch is 0.51 billion tons and 186 million yuan respectively. The optimization range is $1.39 \%$ and $1.09 \%$ respectively. After further increasing the carbon emission reduction target by 9\% (hypothesis 3), the optimized scale of carbon emission reduction and economic dispatch are 331 million tons and 1.395 billion yuan respectively, with an optimization range of $9 \%$ and $8.13 \%$ respectively. In the feasible domain, the optimized compromise solution of the strict target is better than the optimization compromise solution of the loose target, and the optimization effect on the carbon emission reduction and dispatch economy is better.

\section{REFERENCES}

[1] Ding Ran, Kang Chongqing, Zhou Tianrui, Chen Xiaoke, Li Xin Analysis and Prospect on Technical Approaches for Low Carbon Power Grid [J]. Power System Technology, 2011, 35(10): 1-8. (in Chinese)

[2] Hou Jianchao, Shi Dan. Research on the driving factors of carbon emission change in China's power industry [J]. China Industrial Economics, 2014(06): 44-56. (in Chinese)

[3] Liu Zhenya. Accelerating the Construction of Asian Energy Internet [J]. Think Tank Era, 2017(04): 39-40. (in Chinese)

[4] Li Canbing, Liu Yu, Cao Yijia, Tan Yi, Xue Chen, Tang Shengwei Evaluation of the consistency of low-carbon power generation dispatching and energy-saving power generation dispatching $[\mathrm{J}]$. Proceedings of The Chinese Society for Electrical Engineering, 2011, 31(31): 94-101. (in Chinese)

[5] Zhang Xian, Geng Jian, Pang Bo, Xue Bi'ke, Li Zhu. Application and Analysis of Power Generation Transaction in Energy Saving and Emission Reduction in China [J]. Automation of Electric Power Systems, 2014, 38(17): 87-90+129. (in Chinese)

[6] Hu Weidong, Gu Yugui, Xu Liang, Li Zengbin. Analysis of power transactions in 2016 [J]. Electric Power, 2017, 50(04): 35-38. (in Chinese)

[7] Liu Zhenya. UHV AC/DC power grid [M]. China Electric Power Press, 2013. (in Chinese)

[8] X.H. Xia,G.Q. Chen. Energy abatement in Chinese industry: Cost evaluation of regulation strategies and allocation alternatives[J]. Energy Policy,2012,45.

[9] Yang K, Lei Y, Chen W, et al. Carbon dioxide emission reduction quota allocation study on Chinese provinces based on two-stage Shapley information entropy model[J]. Natural Hazards, 2018, 91(1):321-335.

[10] Yang B, Liu C, Su Y, et al. The Allocation of Carbon Intensity Reduction Target by 2020 among Industrial Sectors in China[J]. Sustainability, 2017, 9(1):148.

[11] Shi Y, Yu P L. Goal Setting and Compromise Solutions[M]// Multiple Criteria Decision Making and Risk Analysis Using Microcomputers. Springer Berlin Heidelberg, 1989:165-204. 